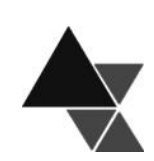

\title{
A produção agrícola e a atuação das Centrais de Abastecimento no Brasil
}

\author{
Altivo Roberto Andrade de Almeida Cunha ${ }^{1}$ e Walter Belik ${ }^{2}$
}

Este artigo apresenta evidências das mudanças que estão se processando no aparato atacadista público de alimentos no Brasil abordando a evolução, as características atuais e as funções do sistema brasileiro de abastecimento. É realizada uma análise com base na observação dos dados coletados junto a 29 centrais de abastecimento públicas brasileiras em 2009 com informações sobre origem e destino dos hortigranjeiros comercializados nesses entrepostos a partir de uma amostra significativa. Os padrões sistêmicos podem ser observados através de dois aspectos: o desempenho da atividade econômica dos principais entrepostos atacadistas brasileiros e as funções remanescentes de reunião e distribuição da produção local e regional. Pretendemos demonstrar que o grupo de centrais públicas de abastecimento é bastante heterogêneo e que, de maneira geral, a dinâmica do seu crescimento é estabelecida "de fora para dentro", sendo que muitos destes equipamentos não mais exercem papéis centrais como executores de políticas públicas voltadas para o abastecimento.

Palavras-chave: abastecimento, CEASAs, produção local.

\section{The agricultural production and the role of the Wholesale Markets in Brazil}

This paper presents some evidences of changes that are occurring in the apparatus of public food wholesaler in Brazil addressing the evolution, characteristics and functions of the current structure of the Brazilian wholesale supply. It is an analysis based on observation data collected from 29 public wholesale in Brazil in 2009 with information on origin and destination of traded horticultural such warehouses from a significant sample. Systemic patterns can be observed through two aspects: the performance of economic activity of the main Brazilian and wholesalers warehouses remaining functions of assembly and distribution of local and regional production. We intend to prove that the group of public power supply is very heterogeneous and that, in general, the dynamics of their growth is established "from outside to inside", many of these devices do not exert more central roles as implementers of public policies for supplies.

Key-words: food supply, Wholesale Markets, local production.

\footnotetext{
${ }^{1}$ Doutor em Economia, Instituto de Economia (IE), Universidade Estadual de Campinas (UNICAMP). Consultor FAO.

2 Professor Titular do Instituto de Economia e Coordenador do NEPA - Núcleo de Estudos e Pesquisas em Alimentação (NEPA), UNICAMP. Correspondência: Rua Pitágoras, 353, Barão Geraldo, Campinas, SP. CEP 13083-857. E-mail: belik@eco.unicamp.br.
} 


\section{APRESENTAÇÃO}

A partir da segunda metade da presente década a comercialização de hortigranjeiros nas principais centrais públicas de abastecimento apresentou um significativo crescimento. Após uma década de estagnação os volumes comercializados voltaram a crescer atingindo a marca de 15,5 milhões de toneladas comercializadas em 2007. Tirante a importância econômica da retomada, o fato merece uma análise mais detalhada, pois há muitas dúvidas sobre a continuidade do modelo de comercialização que foi implementado nos anos 60 no Brasil e que sofreu poucas modificações desde então. Profundas mudanças ocorreram nas últimas décadas no que se refere à comercialização de alimentos, tanto em termos de novos padrões de produção, transformação e logística bem como no lado da demanda, com a introdução de novos produtos e a disseminação de novos hábitos de consumo.

No âmbito mais geral, as relações entre o atacado de alimentos e os elos à sua montante e jusante também vem sendo objeto de estudos. Nos países desenvolvidos muito da "função" do atacado está desaparecendo com o encurtamento da cadeia produtiva e o esmagamento das margens de comercialização. Por outro lado, vêm emergindo com força cada vez maior as atividades de logística que passaram a absorver boa parte daquelas margens que eram apropriadas pelos demais elos do processo produtivo. Evidentemente com o estabelecimento de padrões de qualidade cada vez mais elevados, legislação mais detalhada e com maiores exigências por parte do consumidor, a logística passa ser um aspecto chave não só na comercialização como também na fase de produção de alimentos frescos.

O objetivo desse artigo é apresentar algumas evidências das mudanças que estão se processando no aparato atacadista público de alimentos no Brasil. Pretendemos demonstrar que o grupo de centrais públicas de abastecimento é bastante heterogêneo e que, de maneira geral, a dinâmica do seu crescimento tem sido estabelecida "de fora para dentro", sendo que muitos desses equipamentos não mais exercem papéis centrais como executores de políticas públicas voltadas para o abastecimento. Assim, em um contexto de reforço da agricultura familiar, fica faltando algum tipo de atuação governamental no sentido de apoiar o escoamento dessa produção.
A implantação do sistema público de abastecimento no Brasil é oriunda do Sistema Nacional de Centrais de Abastecimento (SINAC), vigente entre 1972 e 1988, sendo atribuída à empresa estatal Companhia Brasileira de Alimentos (COBAL) as funções de coordenação, controle técnico, administrativo e financeiro do Programa [1]. O sistema brasileiro pressupunha uma hierarquia funcional estabelecida pela relação entre as Centrais de Abastecimento e os "mercados satélites", com atuação geograficamente delimitada e cuja coordenação pressupunha manter um serviço setorial de informação de mercado e de padronização e classificação dos produtos a serem comercializados nas Centrais com a indispensável unidade de ação às entidades integradas [2].

Consoante com o processo de modernização conservadora da agricultura brasileira, o SINAC definiu e impôs padrões e normas técnicas na ausência de um padrão estruturado de mercado. Estabeleceu normas de embalagens, informações de mercado, técnicas de produção e formatos organizacionais que deveriam ser implementados e conduzidos pelas Centrais de Abastecimento, com uma ambiciosa missão de integração dos padrões da base produtiva até a regulação do varejo.

Não cabe nesse artigo analisar as causas do fracasso do SINAC, mas apenas destacar que, em 1988, ao término do SINAC, o sistema atacadista alimentar brasileiro contava com 22 empresas, 47 entrepostos e mercados expedidores e 158 equipamentos varejistas [3]. Atualmente a maior parte desses equipamentos tem apenas a função importadora de alimentos de outras regiões para a distribuição junto ao comércio local, função coincidente com as atividades de atacado exercidas pela iniciativa privada local. Dentre o conjunto de 23 centrais atacadistas analisadas destacam-se o caso de 13 unidades que mantém funções de reunião da produção local, regional e até mesmo nacional para posterior distribuição ao varejo e ao consumidor final.

$\mathrm{Na}$ primeira seção apresentamos uma análise realizada com base na observação dos dados coletados junto a 29 centrais de abastecimento públicas em 2009 [4]. Esta análise partiu de informações sobre origem e destino dos hortigranjeiros comercializados nesses entrepostos a partir de uma amostra significativa. $\mathrm{Na}$ segunda seção são analisados os padrões sistêmicos observados pelo conjunto dessas 29 unidades através de dois aspectos: o desempenho da atividade 
econômica dos principais entrepostos atacadistas brasileiros e as funções remanescentes de reunião e distribuição da produção local e regional. Finalmente, na última seção alinhavamos algumas conclusões importantes para efeito de políticas públicas.

\section{DESEMPENHO E INTERAÇÕES DO SISTEMA}

A estrutura atacadista implantada no Brasil foi concebida como uma rede formal, estruturada em protocolos técnicos e de informação para o abastecimento urbano e para a comercialização da produção hortigranjeira nacional. Os integrantes desta rede cumpriam originalmente distintas funções no abastecimento urbano, dadas por sua hierarquia (ou porte) e pelo papel de reunião e expedição da produção local e regional. Neste sentido, o desempenho econômico do segmento atacadista deveria ser avaliado em termos de comportamento sistêmico, e não apenas pelo desempenho individual de seus integrantes.

O desempenho econômico do sistema, medido pela evolução da quantidade e valor comercializado, foi avaliado em diversos estudos de caso, principalmente para a CEAGESP (Companhia de Entrepostos e Armazéns Gerais de São Paulo), revelando uma tendência até 2005 de decréscimo ou estagnação da movimentação comercial atacadista. Estudos de Chaim [5] demonstraram que entre 1985 e 1997 a movimentação anual de hortigranjeiros se manteve estagnada na CEAGESP. Igualmente Junqueira [6] apontou que a movimentação da CEAGESP em 1998 declinou 15\% em relação à 1991/92. No mesmo sentido, o estudo de Carvalho [7], que analisou dados de comercialização da CEAGESP entre 1985 e 2005, confirmou a tendência de perda de participação desta central na comercialização dos principais produtos hortigranjeiros. Partindo destas evidências, a investigação do desempenho do sistema atacadista procurou avaliar a evolução do quantum e do valor da comercialização atacadista para o conjunto dos principais mercados atacadistas brasileiros para a década de 2000 e os padrões de desempenho comercial dos produtos hortigranjeiros.

Foram reunidos e harmonizados dados das nove principais centrais de abastecimento brasileiras a partir de informações de seus departamentos técnicos, de estudos de caso e do survey realizado para este estudo. As análises indicam que as tendências recentes de crescimento da atividade atacadista não refletem um novo dinamismo no segmento, ao contrário, evidenciam que a dinâmica do comércio atacadista não é mais determinada no âmbito das centrais de abastecimento e sim em outros circuitos comerciais da grande distribuição.

\section{O desempenho econômico do sistema}

Para avaliar o desempenho econômico do sistema foram reunidas diversas bases de dados geradas em oito das vinte principais centrais de abastecimentos brasileiras para o período entre 2000 e 2009, com informações sobre a evolução da movimentação em quantidade e volume financeiro de produtos hortigranjeiros. Embora a herança organizacional do SINAC tenha legado uma boa base metodológica de acompanhamento e registro de informações, há expressivas diferenças no nível de agregação e de disponibilidade temporal dos dados entre as centrais, ocasionando lacunas informacionais expressivas. Os dados reúnem informações das três grandes centrais nacionais, São Paulo, Rio de Janeiro e Contagem, cinco das onze centrais nacionais, Curitiba, Goiânia, Vitória, Porto Alegre, Fortaleza e uma central regional, Uberlândia, que respondem de forma agregada por $58,3 \%$ da movimentação nacional em 2007, calculada em 15,5 milhões de toneladas (Tabela 1).

Os dados físicos e financeiros foram convertidos em índices, tomando como base o ano de 2005, e como critérios comparativos na mesma base foram relacionados como indicadores a taxa de crescimento populacional estimada para os anos 2000 a 2009, a taxa real de crescimento anual do PIB agropecuário e do PIB nacional e o IGP-M³.

Os dados de quantum comercializado no período demonstram algumas evidências relevantes. A primeira é o comportamento agregado do sistema, sendo que de forma geral a comercialização física nas centrais brasileiras experimenta um período de estagnação dos volumes comercializados até meados

\footnotetext{
${ }^{3}$ Os valores da projeção da população entre 2000 e 2009, realizada pelo Instituto Brasileiro de Geografia e Estatística (IBGE), foram convertidos em índices na base 100, sendo $2005 \mathrm{o}$ ano de referência, o mesmo procedimento adotado para os dados do PIB. Para o IGP-M, a taxa de variação foi convertida para a base 100. A escolha de 2005 como ano de referência está associada ao fato de que a CEAGESP só detém informações consolidadas sobre movimentação financeira a partir deste ano, em função da perda de dados anteriores decorrentes de problemas operacionais.
} 
Tabela 1. Comercialização anual de produtos hortigranjeiros em quantidade e valor e preço médio em entrepostos brasileiros, 2000 a 2009.

\begin{tabular}{|c|c|c|c|c|c|c|c|c|c|c|}
\hline Entrepostos & 2000 & 2001 & 2002 & 2003 & 2004 & 2005 & 2006 & 2007 & 2008 & 2009 \\
\hline \multicolumn{11}{|c|}{ Quantidade 1000 Toneladas } \\
\hline São Paulo & 2.322 .363 & 2.389 .658 & 2.325 .529 & 2.258 .706 & 2.373 .228 & 2.482 .927 & 2.523 .345 & 2.561 .086 & 2.648 .236 & 2.715 .042 \\
\hline Contagem & 1.255 .018 & 1.255 .272 & 1.254 .313 & 1.222 .310 & 1.243 .769 & 1.307 .097 & 1.327 .450 & 1.369 .256 & 1.405 .938 & 1.416 .071 \\
\hline Curitiba & 694.839 & 631.328 & 670.773 & 650.334 & 675.771 & 714.701 & 691.820 & 696.531 & 702.780 & 688.824 \\
\hline Goiânia & 608.907 & 655.626 & 765.269 & 751.836 & 774.908 & 756.345 & 771.002 & 762.483 & 750.485 & 763.123 \\
\hline Vitória & n.d. & n.d. & 438.285 & 416.754 & 466.458 & 467.632 & 454.939 & 500.692 & 510.554 & 510.464 \\
\hline Porto Alegre & 494.793 & 515.224 & 514.354 & 504.828 & 508.166 & 512.355 & 518.072 & 505.387 & 533.387 & 513.289 \\
\hline Fortaleza & n.d. & n.d. & 316.550 & 314.400 & 354.461 & 363.903 & 380.227 & 424.641 & 428.696 & 454.664 \\
\hline Uberlândia & 165.942 & 164.466 & 160.511 & 149.629 & 138.097 & 160.274 & 168.995 & 189.998 & 192.147 & 206.080 \\
\hline \multicolumn{11}{|c|}{ Valor da Comercialização R\$ 1000} \\
\hline São Paulo & n.d. & n.d. & n.d. & n.d. & n.d. & 2.520 .380 & 2.648.031 & 2.819 .320 & 3.087 .537 & 3.514 .351 \\
\hline Contagem & 641.887 & 733.327 & 816.142 & 898.923 & 1.018 .000 & 1.101 .601 & 1.140 .036 & 1.249 .740 & 1.410 .004 & 1.516 .181 \\
\hline Curitiba & 389.110 & 391.423 & 462.833 & 526.771 & 614.952 & 650.378 & 636.474 & 703.496 & 737.919 & 606.165 \\
\hline Goiânia & n.d. & n.d. & 557.315 & 649.506 & 695.982 & 743.807 & 787.686 & 874.006 & 961.399 & 977.103 \\
\hline Vitória & n.d. & n.d. & 316.013 & 330.307 & 427.186 & 443.931 & 392.278 & 487.991 & 554.021 & 607.624 \\
\hline Porto Alegre & 275.086 & 309.744 & 365.816 & 396.753 & 462.670 & 490.930 & 472.600 & 528.128 & 582.419 & 630.795 \\
\hline Fortaleza & n.d. & n.d. & 197.373 & 238.129 & 288.421 & 348.043 & 393.588 & 472.657 & 549.752 & 602.022 \\
\hline Uberlândia & 89.979 & 97.973 & 100.441 & 98.477 & 117.605 & 148.822 & 154.007 & 196.239 & 230.066 & 257.794 \\
\hline \multicolumn{11}{|c|}{ Preço médio anual $\mathrm{R} \$ / \mathrm{Kg}$} \\
\hline São Paulo & n.d & n.d & n.d & n.d & n.d & 1,02 & 1,05 & 1,10 & 1,17 & 1,29 \\
\hline Contagem & 0,51 & 0,58 & 0,65 & 0,74 & 0,82 & 0,84 & 0,86 & 0,91 & 1,00 & 1,07 \\
\hline Curitiba & 0,56 & 0,62 & 0,69 & 0,81 & 0,91 & 0,91 & 0,92 & 1,01 & 1,05 & 0,88 \\
\hline Goiânia & n.d. & n.d. & 0,73 & 0,86 & 0,90 & 0,98 & 1,02 & 1,15 & 1,28 & 1,28 \\
\hline Vitória & n.d. & n.d. & 0,72 & 0,79 & 0,92 & 0,95 & 0,86 & 0,97 & 1,09 & 1,19 \\
\hline Porto Alegre & 0,56 & 0,60 & 0,71 & 0,79 & 0,91 & 0,96 & 0,91 & 1,04 & 1,09 & 1,23 \\
\hline Fortaleza & n.d. & n.d. & 0,62 & 0,76 & 0,81 & 0,96 & 1,04 & 1,11 & 1,28 & 1,32 \\
\hline Uberlândia & 0,54 & 0,60 & 0,63 & 0,66 & 0,85 & 0,93 & 0,91 & 1,03 & 1,20 & 1,25 \\
\hline Média & 0,54 & 0,60 & 0,68 & 0,77 & 0,87 & 0,94 & 0,95 & 1,04 & 1,14 & 1,19 \\
\hline
\end{tabular}

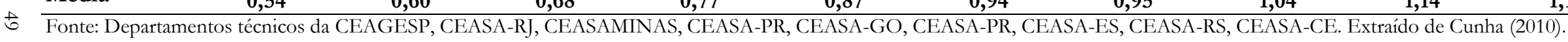


da década de 2000, sucedida por um período de crescimento da quantidade comercializada em taxas de crescimento superiores às taxas estimadas de crescimento populacional brasileiro, mas inferiores na maioria das centrais, ao crescimento do PIB nacional. Este movimento de inversão da tendência de estagnação da comercialização ocorre para a CEAGESP, cuja média do índice de quantum evolui $10,6 \%$ comparando-se o quinquênio 2000/2004 com o seguinte 2005/2009. Performance similar é verificada em Contagem (9,4\%), Vitória (11,7\%), Fortaleza (25,5\%). Permanecem estagnadas as centrais de Curitiba (5,3\%), Rio de Janeiro $(-0,8 \%)$ e Goiânia $(0 \%)$.

Para identificar se esta reversão de tendência é geral ou está baseada em produtos específicos, foram obtidos dados desagregados por grupos de produtos conforme a classificação de cada central.

A partir de informações de dados desagregados, solicitados às três maiores centrais de abastecimento nacionais (São Paulo, Rio de Janeiro e Minas Gerais), a Tabela 2 reúne informações sobre a quantidade comercializada de 2005 a 2009 para os seis produtos de maior consumo per capita identificados pela Pesquisa de Orçamentos Familiares de 2003 (banana, batata, cebola, laranja, maçã e tomate).

Estes produtos, nestes três entrepostos, representam uma movimentação média de 4,5 milhões de toneladas anuais, equivalente a $29 \%$ da comercialização geral de Frutas, Verduras e Legumes (FLV) de todo o sistema de entrepostos brasileiro (ano

Tabela 2. Evolução da comercialização anual de 2005 a 2009 em toneladas dos principais produtos hortigranjeiros para os entrepostos de São Paulo, Rio de Janeiro e Contagem.

\begin{tabular}{|c|c|c|c|c|c|}
\hline Produtos/Entrepostos & 2005 & 2006 & 2007 & 2008 & 2009 \\
\hline \multicolumn{6}{|l|}{ São Paulo } \\
\hline Banana & 86.814 & 79.719 & 84.593 & 77.994 & 79.841 \\
\hline Batata & 223.642 & 233.118 & 228.335 & 226.192 & 211.272 \\
\hline Cebola & 92.211 & 87.610 & 89.518 & 89.242 & 89.784 \\
\hline Laranja & 314.979 & 302.205 & 303.402 & 322.372 & 366.172 \\
\hline Maçã & 138.922 & 124.471 & 134.640 & 123.026 & 132.351 \\
\hline Tomate & 267.135 & 275.387 & 272.877 & 275.707 & 293.471 \\
\hline Total São Paulo & 1.123 .702 & 1.102 .510 & 1.113 .364 & 1.114 .535 & 1.172 .890 \\
\hline \multicolumn{6}{|l|}{ Rio de Janeiro } \\
\hline Banana & 94.821 & 96.635 & 104.485 & 106.691 & 115.837 \\
\hline Batata & 271.559 & 283.514 & 283.666 & 286.697 & 258.692 \\
\hline Cebola & 80.236 & 82.886 & 83.752 & 76.716 & 73.900 \\
\hline Laranja & 140.584 & 134.037 & 147.033 & 162.586 & 195.893 \\
\hline Maçã & 54.270 & 53.383 & 68.992 & 58.454 & 62.515 \\
\hline Tomate & 105.485 & 120.526 & 109.407 & 103.309 & 108.810 \\
\hline Total Rio de Janeiro & 746.954 & 770.982 & 797.335 & 794.453 & 815.647 \\
\hline \multicolumn{6}{|l|}{ Contagem (MG) } \\
\hline Banana & 121.683 & 113.552 & 120.075 & 123.667 & 129.059 \\
\hline Batata & 185.997 & 191.642 & 190.447 & 198.333 & 178.077 \\
\hline Cebola & 64.913 & 66.276 & 67.166 & 63.582 & 67.151 \\
\hline Laranja & 125.212 & 126.048 & 135.512 & 135.330 & 140.348 \\
\hline Maçã & 61.615 & 55.138 & 68.508 & 65.432 & 69.219 \\
\hline Tomate & 96.811 & 105.519 & 103.023 & 104.001 & 113.447 \\
\hline Total Contagem & 656.230 & 658.174 & 684.732 & 690.346 & 697.301 \\
\hline
\end{tabular}

Fonte : Departamento técnico da CEAGESP/CEASAMINAS/ CEASA-RJ. Extraído Cunha (2010). 
base 2007). A partir de uma análise comparativa da evolução da comercialização destes produtos, tomando como referência de dinamismo a posição da média quinquenal comercializada em relação à taxa de crescimento populacional anual, como proxy conservadora de consumo (pois não considera o efeito renda) e o crescimento do PIB observa-se o seguinte:

Os dados da CEAGESP indicam uma queda na comercialização de cinco dos seis produtos, sendo que em três deles, banana, cebola e maçã, há redução absoluta na comercialização e em dois (batata e laranja) há crescimento médio abaixo da taxa de crescimento populacional ou decrescimento relativo. $\mathrm{O}$ único produto que experimenta um crescimento moderado é o tomate. Esta redução decorre de dois fatores: a competição da zona atacadista fora da CEAGESP e, principalmente, pela crescente importância dos circuitos comerciais do setor supermercadista, através da compra direta de produtores ou de traders especializados. Nesse sentido, o recente vigor da comercialização da CEAGESP estaria baseado na diversificação de seu mix comercial, que complementa a pauta de comercialização das FLV nos supermercados em produtos onde não foi possível estabelecer circuitos privados próprios.

Nos entrepostos do Rio de Janeiro e de Contagem é verificado comportamento similar ao paulista de decrescimento na oferta de batata e cebola e de crescimento da comercialização de tomate, moderado no Rio de Janeiro e vigoroso em Contagem. No Rio de Janeiro ainda é verificado um comportamento dinâmico na comercialização de frutas, como anteriormente constatado, com crescimento vigoroso das vendas de banana, laranja e maçã.

É importante observar que o crescimento da oferta dos principais produtos nos três maiores entrepostos é influenciado por fatores produtivos e/ou comerciais próprios de suas cadeias produtivas e que vão determinar sua dinâmica no comércio atacadista. Um exemplo é o caso da laranja, que apresentou crescimento de oferta de 63 mil toneladas entre 2007 e 2009 em São Paulo (um incremento de $21 \%$ ), montante equivalente a $40 \%$ do crescimento líquido da comercialização total do entreposto paulistano. No mesmo período no Rio de Janeiro a oferta de laranja cresceu 49 mil toneladas, um incremento de $33 \%$. Este movimento reflete a crise de preços da citricultura industrial paulista no período e a destinação de parte dos frutos de destino industrial para o consumo de mesa. Quando analisada a evolução dos volumes financeiros, verifica-se que os dados gerais são extremamente similares (ainda que as séries históricas não sejam completas para todos os entrepostos) com uma contínua elevação dos valores comercializados, com taxas de crescimento acima do IGP-M e do Índice de Preços ao Consumidor Ampliado (IPCA) no período. O preço médio dos produtos hortigranjeiros comercializados nas principais centrais de abastecimento passa de $\mathrm{R} \$ 0,54$ em 2000 para R\$ 1,22 em 2009, sendo que em São Paulo, entre 2005 e 2009, evolui de $\mathrm{R} \$ 1,02$ para $\mathrm{R} \$$ 1,29. Convertidos em números, índice com base em 2005, observa-se que o preço médio por quilograma comercializado segue o mesmo padrão nas centrais de abastecimento, superando no período a evolução do IPCA, do IGP-M e do PIB no período (Tabelas 3 e 4).

Tabela 3. Preço médio $\mathrm{R} \$ / \mathrm{Kg}$ para produtos hortigranjeiros comercializados em entrepostos atacadistas brasileiros selecionados, 2000 a 2005.

\begin{tabular}{lllllllllll}
\hline \multicolumn{1}{c}{ Entreposto } & $\mathbf{2 0 0 0}$ & $\mathbf{2 0 0 1}$ & $\mathbf{2 0 0 2}$ & $\mathbf{2 0 0 3}$ & $\mathbf{2 0 0 4}$ & $\mathbf{2 0 0 5}$ & $\mathbf{2 0 0 6}$ & $\mathbf{2 0 0 7}$ & $\mathbf{2 0 0 8}$ & $\mathbf{2 0 0 9}$ \\
\hline São Paulo & n.d. & n.d. & n.d. & n.d. & n.d. & 1,02 & 1,05 & 1,10 & 1,17 & 1,29 \\
Contagem & 0,51 & 0,58 & 0,65 & 0,74 & 0,82 & 0,84 & 0,86 & 0,91 & 1,00 & 1,07 \\
Goiânia & n.d. & n.d. & 0,73 & 0,86 & 0,90 & 0,98 & 1,02 & 1,15 & 1,28 & 1,28 \\
Curitiba & 0,56 & 0,62 & 0,69 & 0,81 & 0,91 & 0,91 & 0,92 & 1,01 & 1,05 & 0,88 \\
Vitória & n.d. & n.d. & 0,72 & 0,79 & 0,92 & 0,95 & 0,86 & 0,97 & 1,09 & 1,19 \\
Porto Alegre & 0,56 & 0,60 & 0,71 & 0,79 & 0,91 & 0,96 & 0,91 & 1,04 & 1,09 & 1,23 \\
Fortaleza & n.d. & n.d. & 0,62 & 0,76 & 0,81 & 0,96 & 1,04 & 1,11 & 1,28 & 1,32 \\
Uberlândia & 0,54 & 0,60 & 0,63 & 0,66 & 0,85 & 0,93 & 0,91 & 1,03 & 1,20 & 1,25 \\
\hline Média & $\mathbf{0 , 5 4}$ & $\mathbf{0 , 5 9}$ & $\mathbf{0 , 6 8}$ & $\mathbf{0 , 7 7}$ & $\mathbf{0 , 8 7}$ & $\mathbf{0 , 9 5}$ & $\mathbf{0 , 9 5}$ & $\mathbf{1 , 0 5}$ & $\mathbf{1 , 1 6}$ & $\mathbf{1 , 1 9}$ \\
\hline
\end{tabular}

Fonte: Departamento técnico da CEAGESP, CEASAMINAS, CEASA-GO, CEASA-PR, CEASA-ES, CEASA-RS, CEASA-CE. Extraído de Cunha (2010). 
Tabela 4. Índice base 2005 do Preço médio $\mathrm{R} \$ / \mathrm{Kg}$ para produtos hortigranjeiros comercializados em entrepostos atacadistas brasileiros selecionados, 2000 a 2005.

\begin{tabular}{lcccccccccc}
\hline Entreposto & $\mathbf{2 0 0 0}$ & $\mathbf{2 0 0 1}$ & $\mathbf{2 0 0 2}$ & $\mathbf{2 0 0 3}$ & $\mathbf{2 0 0 4}$ & $\mathbf{2 0 0 5}$ & $\mathbf{2 0 0 6}$ & $\mathbf{2 0 0 7}$ & $\mathbf{2 0 0 8}$ & $\mathbf{2 0 0 9}$ \\
\hline São Paulo & - & - & - & - & - & 100 & 103 & 108 & 115 & 128 \\
Contagem & 61 & 69 & 77 & 87 & 97 & 100 & 102 & 108 & 119 & 127 \\
Goiânia & - & - & 74 & 88 & 91 & 100 & 104 & 117 & 130 & 130 \\
Curitiba & 62 & 68 & 76 & 89 & 100 & 100 & 101 & 111 & 115 & 97 \\
Vitória & - & - & 76 & 83 & 96 & 100 & 91 & 103 & 114 & 125 \\
Porto Alegre & 58 & 63 & 74 & 82 & 95 & 100 & 95 & 109 & 114 & 128 \\
Fortaleza & - & - & 65 & 79 & 85 & 100 & 108 & 116 & 134 & 138 \\
Uberlândia & 58 & 64 & 67 & 71 & 92 & 100 & 98 & 111 & 129 & 135 \\
\hline Média & $\mathbf{6 0}$ & $\mathbf{6 6}$ & $\mathbf{7 3}$ & $\mathbf{8 3}$ & $\mathbf{9 4}$ & $\mathbf{1 0 0}$ & $\mathbf{1 0 0}$ & $\mathbf{1 1 0}$ & $\mathbf{1 2 1}$ & $\mathbf{1 2 6}$ \\
\hline Referências & & & & & & & & & & 121 \\
\hline IGP-M & 54 & 59 & 65 & 82 & 89 & 100 & 104 & 112 & 123 & 112 \\
IPCA Índice Geral & 66 & 71 & 80 & 88 & 95 & 100 & 103 & 108 & 114 & 119 \\
PIB Geral & 86 & 90 & 90 & 92 & 93 & 100 & 102 & 107 & 112 & 111 \\
\hline
\end{tabular}

Fonte: IBGE/Departamento técnico da CEAGESP, CEASAMINAS, CEASA-GO, CEASA-PR, CEASA-ES, CEASA-RS, CEASACE. Extraído Cunha (2010).

As conclusões sobre a evolução recente da comercialização do sistema convergem para as seguintes constatações:

1) há uma elevação do patamar de comercialização de hortigranjeiros nas principais centrais de abastecimento em números absolutos, que ocorre a partir de 2004/2005, superando a estagnação ou decrescimento verificado na primeira metade da década de 2000;

2) há um crescimento real no volume financeiro da comercialização de produtos hortigranjeiros, influenciado pelo crescimento da oferta de produtos de maior valor unitário como frutas, nacionais e importadas;

3) o crescimento de quantum e valor parece estar ancorado no câmbio favorável à importação e no crescimento da renda e não em ganhos de eficiência comercial ou competitiva;

4) embora a escala de comercialização nas centrais de abastecimento seja expressiva, a diminuição ou o crescimento moderado do volume comercializado dos principais produtos hortigranjeiros consumidos (batata, cebola, maçã, banana, laranja) indica que a dinâmica do comércio atacadista - à exceção do tomate - não é mais puxada e determinada no âmbito das centrais de abastecimento e sim em outros circuitos comerciais da grande distribuição.
5) as centrais de abastecimento se especializaram como centros comerciais relevantes para uma pauta relativamente restrita de produtos em termos de significância comercial, tornando-se centros de comercialização atacadista de produtos de consumo básico mais do que de especiarias.

\section{RELAÇÕES DE FORNECIMENTO: ORIGEM E DISTÂNCIA DA OFERTA}

Um dos aspectos centrais da discussão sobre a importância das centrais de abastecimento refere-se ao seu papel como centralizador e distribuidor da produção hortigranjeira. Duas dimensões são relevantes para a análise desta questão e devem ser analisadas em separado: a) as transações entre os entrepostos atacadistas, que ocorrem tanto como transações intra empresariais (atacadistas com filiais em vários entrepostos) e inter empresariais e; b) as relações de fornecimento entre a base produtora, local e regional, e a central de abastecimento.

No primeiro caso vale destacar a importância das grandes centrais de abastecimento brasileiras que cumprem o papel de bubs primários e secundários no sistema de abastecimento, com o reconhecimento destacado da importância da CEAGESP como "nó" central.

Em estudo de Cunha \& Campos ${ }^{[8]}$ para o caso da CEASAMINAS, foi demonstrado que 5,2\% do valor total dos produtos hortigranjeiros comercializados no entreposto mineiro de Contagem 
foram fornecidos pelo sistema atacadista de São Paulo, principalmente a CEAGESP. Esta identificação só foi possível porque os municípios de origem (registrados pelas estatísticas de entrada da CEAGESP) que sediam grandes centrais de abastecimento (São Paulo, Contagem, Rio de Janeiro e Cariacica-ES), têm pouca ou nenhuma produção hortícola sendo, portanto, indicativos de repasse atacadista. A grande limitação das estatísticas das centrais de abastecimento referentes ao fornecimento geográfico dos produtos está na incapacidade de identificar a origem de parte dos produtos, uma vez que as notas ou romaneios de entrada apontam o último destino de expedição e não necessariamente a origem da produção.

Segundo levantamento de dados primários sobre a origem de fornecimento de produtos para a CEAGESP para o ano de 2005, 12,7\% do volume ofertado (233,5 mil toneladas) são classificados como "transferência entre entrepostos", sendo apontada como a principal origem dos produtos comercializados e que acabam entrando no Entreposto Terminal de São Paulo (ETSP) com nota de atacadistas locais. Essas cifras se reduzem para 4,3\% do total comercializado representando $134 \mathrm{mil}$ toneladas em 2009. Para o entreposto da Grande BH (Contagem), no ano de 2005 os produtos "sem procedência definida" corresponderam a $41 \%$ da oferta local (1,036 milhões de toneladas). Uma parte relevante da origem não identificada provém do comércio inter entrepostos e, especialmente, do comércio de frutas importadas. No entreposto de Contagem, em 2005, os produtos oriundos da Argentina (única origem internacional identificada naquele ano) representaram apenas $0,05 \%$ da oferta total (2.305 toneladas), mas a comercialização de frutas importadas foi sete vezes superior no mesmo ano (14.842 toneladas), representando $5,8 \%$ do total comercializado. Isto sem contar a comercialização do alho importado de origem chinesa. Ou seja, seis sétimos dos produtos importados na CEASAMINAS foram provenientes de distribuidores nacionais e parte expressiva deles, segundo análise de técnicos da CEASAMINAS, provém de distribuidores do sistema atacadista de São Paulo. Dentro do padrão de coleta de dados das centrais de abastecimento não há, atualmente, uma alternativa metodológica para apurar diretamente a relevância do comércio inter entrepostos (seja intra ou inter empresariais), podendo ser estimada apenas pela diferença entre a origem internacional e a tipificação de produtos importados ou através dos dados indiretos de municípios de origem sem base agrícola. Ainda que parte das informações sobre o fornecimento de produtos hortigranjeiros não seja precisa em relação à origem, principalmente dos produtos importados, as centrais de abastecimento mantêm bases de dados importantes sobre a oferta nacional. Geralmente os estudos técnicos sobre origem dos produtos comercializados nas centrais atacadistas enfatizam a análise proporcional da oferta municipal, sem evidenciar as suas implicações espaciais. No estudo realizado por Cunha \& Campos calculou-se a distância rodoviária ponderada da oferta dos doze principais produtos comercializados na CEASAMINAS, entre o município de origem até o entreposto da Grande Belo Horizonte para o ano de 2006. O estudo identificou que, na média anual, o tomate circula $140 \mathrm{~km}$ dos municípios de origem até o entreposto, a batata $402 \mathrm{~km}$, a cebola $1.301 \mathrm{~km}$ e o abacaxi, $1.538 \mathrm{~km}$.

Utilizando o mesmo referencial metodológico, e a exemplo da relação dos dez principais produtos, foram coletadas no survey informações sobre os dez principais municípios fornecedores para os 23 entrepostos nacionais para 2007. Para o conjunto dos entrepostos pesquisados, a participação dos dez principais municípios fornecedores está em 29,8\% sobre o total, sendo que quanto menor é o volume de comercialização do entreposto, maior vai ser essa participação. Para os cinco "Mercados Locais" identificados na amostra, a participação dos dez maiores fornecedores no total comercializado chega a 68,4\%. Outro exercício interessante foi o levantamento dos maiores municípios em termos de fornecimento ao sistema. Nesse sentido, foram relacionados os municípios que ofertam quantidades de produtos iguais ou superiores ao 10 을 fornecedor da maior central de abastecimento (CEAGESP), estando relacionados 32 municípios, que representam $14 \%$ da oferta nacional de produtos hortigranjeiros (Tabela 5).

Algumas constatações são relevantes. Em primeiro lugar, é realçada a importância da oferta oriunda do polo de fruticultura irrigada de Juazeiro (BA) e Petrolina (PE), que agregadamente respondem por 13,3\% da oferta total. O município de Piedade é o grande fornecedor do ETSP, mas o próprio sistema atacadista de São Paulo, incluída a CEAGESP, é considerado como a quarta maior origem de produtos ( $5 \%$ do total) e com a maior amplitude de distribuição, 
com oito destinos. Outras posições destacadas são de São Gotardo (MG) e Cristalina (GO), importantes polos de produção de batata. Ou seja, a composição do mix de comercialização das centrais de abastecimento tem participação expressiva de polos nacionais especializados de produção hortigranjeira, juntamente com a distribuição da produção regional do entorno das centrais.

\section{Base regional do fornecimento}

Para avaliar a importância relativa do abastecimento da produção local e regional nas centrais de abastecimento, foram reunidas informações de quantidade ofertada de 227 municípios para as 23 centrais pesquisadas.

Os dados de oferta em quantidade dos 10 principais municípios de cada central (M10+) foram ponderados pela distância rodoviária entre a sede do município fornecedor e a central de abastecimento respectiva, "roteirizadas" individualmente por um software especializado, gerando um indicador de distância média ponderada da oferta em quilômetros. $\mathrm{O}$ resultado encontrado mostra, a título de exemplificação, três tipos de centrais com diferentes padrões de oferta ponderada pela distância: São Paulo, maior central, cuja oferta média ponderada para os 10 maiores fornecedores é de 189,2 km, sendo todos fornecedores estaduais; Curitiba, sétimo entreposto nacional em movimentação, e que apresenta uma distância média ponderada de $39,2 \mathrm{~km}$, a quarta menor média nacional (e a menor entre as grandes centrais) e Caruaru, Central Regional que tem a maior distância média ponderada de oferta: $912 \mathrm{~km}$.

A Tabela 6 apresenta a relação consolidada da distância média ponderada de oferta para 23 centrais, relacionando o peso proporcional da oferta nas distâncias em três faixas: Até $100 \mathrm{~km}$, considerado como fornecimento local; mais de $100 \mathrm{~km}$ até $300 \mathrm{~km}$, como expressão do fornecimento regional e mais de $300 \mathrm{~km}$.

Os dados da Tabela 6 possibilitam diversas análises sobre o papel das centrais de abastecimento em relação à reunião da produção local e regional, dando margem a estudos de caso comparativos. Por exemplo, na análise dos casos extremos, dois entrepostos de pequeno porte - Caxias do Sul (RS) e Cachoeiro de Itapemirim (ES) - têm praticamente a totalidade de seu fornecimento local (distância ponderada de até $100 \mathrm{~km}$ ), sendo que a primeira é a única central nacional em operação gerida por um consórcio intermunicipal. Em outro extremo estão as centrais de Contagem, na Grande Belo Horizonte, e Salvador, com contribuição nula no índice dos 10 principais municípios para os $100 \mathrm{~km}$ de raio de fornecimento.

\section{Tipologia operacional das Centrais de Abastecimento brasileiras}

A localização das grandes centrais de abastecimento brasileiras foi originalmente definida pela concentração da população consumidora, tendo as funções de reunir a produção local e regional, bem como compor um mix diversificado de oferta para abastecer de forma diversificada e a custos reduzidos. Os mercados do produtor, por sua vez, teriam como função primordial a reunião da produção local e expedição para outros centros atacadistas. No entanto, a perda da coordenação do sistema fez com que os entrepostos desenvolvessem características operacionais próprias, alterando os planos originais de instalação e se afastando significativamente de suas funções originais previstas.

Para definir um parâmetro comparativo da relevância da função de reunião da produção local dos entrepostos, foi considerada a importância proporcional da oferta dos M10+ situados até $100 \mathrm{~km}$ do entreposto. Nesta faixa estão 93 municípios ofertantes, representando $41 \%$ do número total de municípios nominados na pesquisa e $41 \%$ do fornecimento de hortigranjeiros (Tabela 7).

Em relação à relevância da função de reunião da produção regional, foi considerada a importância proporcional da oferta dos 10 principais municípios fornecedores no entreposto situados entre $100 \mathrm{~km}$ e $300 \mathrm{~km}$ (limite próximo da distância média ponderada nacional, de $309 \mathrm{~km})$. Nesta faixa relacionam-se 55 municípios, representando $24 \%$ do número total de municípios e, na média agregada $25 \%$ do fornecimento de hortigranjeiros. As categorias de reunião local e regional foram definidas pelos critérios abaixo (Quadro 1): 
Tabela 5. Principais municípios ofertantes para 23 entrepostos brasileiros, 2007.

\begin{tabular}{|c|c|c|c|c|c|}
\hline Número & Municípios & Toneladas & $\begin{array}{c}\text { Participação } \\
(\%)\end{array}$ & $\begin{array}{c}\% \\
\text { Acumulado }\end{array}$ & $\begin{array}{c}\text { Centrais } \\
\text { abastecidas }\end{array}$ \\
\hline 1 & Juazeiro - BA & 258.537 & 0,08 & 0,08 & 3 \\
\hline 2 & Petrolina - PE & 179.333 & 0,05 & 0,13 & 4 \\
\hline 3 & Piedade - SP & 169.367 & 0,05 & 0,18 & 2 \\
\hline 4 & São Paulo - SP & 162.372 & 0,05 & 0,23 & 8 \\
\hline 5 & São Gotardo - MG & 86.084 & 0,03 & 0,26 & 4 \\
\hline 6 & Sento Sé - BA & 85.000 & 0,03 & 0,29 & 1 \\
\hline 7 & Santa Maria do Jetibá - ES & 83.053 & 0,03 & 0,31 & 1 \\
\hline 8 & Limeira - SP & 81.089 & 0,02 & 0,34 & 1 \\
\hline 9 & Casa Branca - SP & 75.833 & 0,02 & 0,36 & 2 \\
\hline 10 & Cristalina - GO & 74.347 & 0,02 & 0,38 & 4 \\
\hline 11 & Ibiúna - SP & 67.530 & 0,02 & 0,40 & 1 \\
\hline 12 & Ipuiuna - MG & 59.297 & 0,02 & 0,42 & 2 \\
\hline 13 & Itaberaba - BA & 53.357 & 0,02 & 0,44 & 1 \\
\hline 14 & Casa Nova - BA & 52.000 & 0,02 & 0,45 & 1 \\
\hline 15 & Carandaí - MG & 50.483 & 0,02 & 0,47 & 1 \\
\hline 16 & Linhares - ES & 48.678 & 0,01 & 0,48 & 2 \\
\hline 17 & São Miguel Arcanjo - SP & 44.927 & 0,01 & 0,50 & 1 \\
\hline 18 & Teresópolis - RJ & 41.177 & 0,01 & 0,51 & 1 \\
\hline 19 & Ribeirão Branco - SP & 40.359 & 0,01 & 0,52 & 1 \\
\hline 20 & Apiá - SP & 39.507 & 0,01 & 0,53 & 1 \\
\hline 21 & Porto Feliz - SP & 37.868 & 0,01 & 0,54 & 1 \\
\hline 22 & Pirangi - SP & 36.632 & 0,01 & 0,56 & 1 \\
\hline 23 & São José dos Pinhais - SP & 36.405 & 0,01 & 0,57 & 1 \\
\hline 24 & Goianápolis - GO & 36.240 & 0,01 & 0,58 & 1 \\
\hline 25 & Goiânia - GO & 35.390 & 0,01 & 0,59 & 1 \\
\hline 26 & Domingos Martins - ES & 33.900 & 0,01 & 0,60 & 1 \\
\hline 27 & Bom Jesus da Lapa - BA & 33.038 & 0,01 & 0,61 & 1 \\
\hline 28 & Caxias do Sul - RS & 32.910 & 0,01 & 0,62 & 1 \\
\hline 29 & Nova Friburgo - RJ & 32.026 & 0,01 & 0,63 & 1 \\
\hline 30 & Sumidouro - RJ & 31.508 & 0,01 & 0,64 & 1 \\
\hline 31 & Rio Paranaíba - MG & 30.857 & 0,01 & 0,65 & 1 \\
\hline 32 & Vista Alegre do Alto - SP & 30.736 & 0,01 & 0,66 & 1 \\
\hline Total & & 2.159 .839 & & & \\
\hline
\end{tabular}

Fonte: Pesquisa primária. Extraído de Cunha (2010). 
Tabela 6. Distância média ponderada de fornecimento dos 10 principais municípios fornecedores no total comercializado por entreposto, por tipo e participação relativa por estratos de distância, 2007.

\begin{tabular}{|c|c|c|c|c|c|c|c|}
\hline Entreposto & $\begin{array}{l}\text { Rank } \\
2007\end{array}$ & Porte & $\begin{array}{l}10 \text { Principais } \\
\text { municípios } \\
\text { fornecedores }\end{array}$ & $\begin{array}{c}\text { Distância média } \\
\text { ponderada } \\
\text { da oferta }(\mathrm{km})\end{array}$ & $\begin{array}{c}\% \text { até } \\
100 \mathrm{~km}\end{array}$ & $\begin{array}{c}\% \text { de } 101 \\
\text { a } 300 \\
\text { km } \\
\end{array}$ & $\begin{array}{c}\text { Acima } \\
\text { de } 300 \\
\text { km }\end{array}$ \\
\hline São Paulo & 1 & GCN & 0,19 & 189,15 & 0,39 & 0,35 & 0,26 \\
\hline Rio de Janeiro & 2 & GCN & 0,22 & 562,81 & 0,12 & 0,18 & 0,70 \\
\hline Contagem & 3 & GCN & 0,18 & 537,29 & 0,00 & 0,33 & 0,67 \\
\hline Juazeiro & 4 & $\mathrm{CN}$ & 0,63 & 101,67 & 0,67 & 0,29 & 0,04 \\
\hline Recife & 5 & $\mathrm{CN}$ & 0,28 & 524,36 & 0,38 & 0,00 & 0,62 \\
\hline Goiânia & 6 & $\mathrm{CN}$ & 0,30 & 79,58 & 0,78 & 0,22 & 0,00 \\
\hline Curitiba & 7 & $\mathrm{CN}$ & 0,30 & 39,20 & 0,97 & 0,03 & 0,00 \\
\hline Campinas & 8 & $\mathrm{CN}$ & 0,21 & 148,07 & 0,54 & 0,31 & 0,15 \\
\hline Cariacica & 9 & $\mathrm{CN}$ & 0,47 & 199,04 & 0,71 & 0,13 & 0,16 \\
\hline Porto Alegre & 10 & $\mathrm{CN}$ & 0,20 & 117,15 & 0,40 & 0,60 & 0,00 \\
\hline Maracanaú & 11 & $\mathrm{CN}$ & 0,30 & 808,60 & 0,06 & 0,26 & 0,68 \\
\hline Brasília & 12 & $\mathrm{CN}$ & 0,65 & 654,50 & 0,13 & 0,18 & 0,69 \\
\hline Salvador & 13 & $\mathrm{CN}$ & 0,65 & 405,71 & 0,00 & 0,42 & 0,58 \\
\hline Uberlândia & 17 & $\mathrm{CR}$ & 0,38 & 63,89 & 0,76 & 0,20 & 0,04 \\
\hline Campo Grande & 24 & CR & 0,55 & 17,26 & 0,89 & 0,11 & 0,00 \\
\hline Caruaru & 25 & CR & 0,59 & 912,09 & 0,12 & 0,14 & 0,74 \\
\hline Maringá & 26 & CR & 0,41 & 718,68 & 0,19 & 0,00 & 0,81 \\
\hline Juiz de Fora & 32 & $\mathrm{CR}$ & 0,60 & 215,45 & 0,48 & 0,34 & 0,18 \\
\hline Caxias do Sul & 43 & ML & 0,69 & 14,32 & 0,99 & 0,01 & 0,00 \\
\hline Governador Valadares & 44 & ML & 0,85 & 301,86 & 0,09 & 0,17 & 0,74 \\
\hline Joinville & 47 & ML & 0,71 & 378,21 & 0,12 & 0,12 & 0,76 \\
\hline Caratinga & 49 & ML & 0,77 & 91,32 & 0,74 & 0,04 & 0,22 \\
\hline Cachoeiro de Itapemirim & 55 & ML & 0,26 & 31,34 & 1,00 & 0,00 & 0,00 \\
\hline Média & & & 0,45 & 309,20 & 0,46 & 0,19 & 0,35 \\
\hline
\end{tabular}

Fonte: Pesquisa primária. Extraído de Cunha (2010).

Legenda: GCN - Grande Central Nacional; CN - Central Nacional; CR - Central Regional; ML - Mercado Local.

Tabela 7. Distribuição do número de municípios fornecedores por categorias de distância média ponderada e participação na oferta aos entrepostos selecionados.

\begin{tabular}{lcccc}
\hline \multirow{2}{*}{ Categorias } & \multicolumn{2}{c}{ Municípios fornecedores } & \multicolumn{2}{c}{ Ofertas } \\
\cline { 2 - 5 } & Número & $\mathbf{\%}$ & Toneladas & $\mathbf{\%}$ \\
\hline Até $100 \mathrm{~km}$ & 93 & 0,41 & 1.503 .934 & 0,41 \\
Mais de 100 até $300 \mathrm{~km}$ & 55 & 0,24 & 905.734 & 0,25 \\
Mais de 300 até $600 \mathrm{~km}$ & 43 & 0,19 & 656.033 & 0,18 \\
Mais de 600 até $900 \mathrm{~km}$ & 15 & 0,07 & 306.078 & 0,08 \\
Mais de $900 \mathrm{~km}$ & 21 & 0,09 & 260.085 & 0,07 \\
\hline Total & $\mathbf{2 2 7}$ & $\mathbf{1 , 0 0}$ & $\mathbf{3 . 6 3 1 . 8 6 4}$ & $\mathbf{1 , 0 0}$ \\
\hline
\end{tabular}

Fonte: Pesquisa primária. Extraído de Cunha (2010). 


\begin{tabular}{|c|c|c|}
\hline $\begin{array}{c}\text { Reunião } \\
\text { local }\end{array}$ & $\begin{array}{l}\text { Intensa } \\
\text { Moderada } \\
\text { Fraca }\end{array}$ & $\begin{array}{l}\text { Participação Oferta M10+ }(100 \mathrm{~km})>66 \% \text { da oferta total } \\
\text { Participação Oferta dos M10+ }(100 \mathrm{~km}) 33 \%>\text { e }<66 \% \text { da oferta total } \\
\text { Participação Oferta dos M10+ }(100 \mathrm{~km})<33 \% \text { da oferta total }\end{array}$ \\
\hline $\begin{array}{l}\text { Reunião } \\
\text { regional }\end{array}$ & $\begin{array}{l}\text { Intensa } \\
\text { Moderada } \\
\text { Fraca }\end{array}$ & $\begin{array}{l}\text { Participação Oferta M10+ }(100 \mathrm{~km} \text { a } 300 \mathrm{~km})>30 \% \text { da oferta total } \\
\text { Participação Oferta dos M10+(100 km a } 300 \mathrm{~km}) 15 \%>\text { e }<30 \% \text { da oferta total } \\
\text { Participação Oferta dos M10+(100 km })<15 \% \text { da oferta total }\end{array}$ \\
\hline
\end{tabular}

Quadro 1. Delimitação das categorias de reunião local e regional da produção nas Centrais de Abastecimento.

A maior parte das centrais completa seu mix de oferta por meio da importação extra regional, para o consumo local ou para reexportação. No entanto, alguns entrepostos têm pequeno papel de reunião local ou regional e função mais intensa de importação de produtos. Os entrepostos com função de importação predominante foram definidos como aqueles que têm função fraca ou moderada, concomitantemente para as funções de reunião local e regional. Os indicadores de distribuição são expressos pelos índices de internalização e externalização da produção, dadas pela relação entre volume anual comercializado e população da região de inserção do entreposto. Os índices extremos de externalização foram considerados como indicadores de predominância da função de expedição de produtos; enquanto os índices de internalização forte foram considerados indicadores de predomínio de consumo local.

Finalmente, como indicador de função de exportação, foram relacionados entrepostos situados em municípios apontados como origem de fornecimento para outros entrepostos, conforme o número de ocorrências. São Paulo é fornecedor de oito entrepostos, sendo considerado exportador forte e Contagem, Cariacica e Curitiba fornecem para dois outros entrepostos cada um, considerados então exportadores médios. O Quadro 2 reúne estas categorias em uma tipologia funcional síntese para 23 dos entrepostos atacadistas brasileiros.

Os tipos identificados nesta classificação devem ser analisados como partes de um continum e são os tipos extremos, e menos frequentes, que estabelecem referências de posição funcional dos entrepostos.
Um grupo típico é dado pelos entrepostos que têm pouca importância como agente de reunião da produção local e regional, exercendo apenas a função de importador comercial. Os casos extremos são representados por alguns mercados de pequeno porte, originalmente concebidos como mercados do produtor, mas que se transformaram em simples entrepostos comerciais sem relações comerciais expressivas com seu entorno agrícola. É o caso de Caruaru (PE), Maringá (PR), Joinville (SC) - todos com função de reunião local e regional fraca - e o entreposto de Governador Valadares (MG), com função de reunião local fraca e regional moderada.

Este papel de importador predominante é encontrado também em grandes centrais que têm articulação moderada com a base produtora, e são fim de linha no processo de distribuição, caso dos entrepostos do Rio de Janeiro, Maracanaú (CE) e Brasilia. Esta fraca articulação com a base produtiva também é encontrada em Recife, entreposto de importação predominante, mas com papel moderado de reunião da produção local. Salvador tem como característica uma relação intensa com a base produtiva regional, mas pode ser considerado também fim de linha de distribuição, sendo uma central de função de abastecimento local.

O outro extremo é representado pelos entrepostos que mantiveram articulação intensa com a base produtiva local e função expedidora, sendo encontrados nesta categoria "mercados do produtor" clássicos. São exemplos os mercados de Juazeiro, Uberlândia, Caxias do Sul, Caratinga e Cachoeiro de Itapemirim. É interessante observar que algumas centrais sediadas em grandes centros urbanos também exercem as funções de reunião local, caso dos entrepostos de Campo Grande, Goiânia, Curitiba e 


\begin{tabular}{|c|c|c|c|c|c|c|}
\hline \multirow{2}{*}{ Porte } & \multirow{2}{*}{ Entreposto } & \multicolumn{2}{|c|}{ Reúne } & \multirow{2}{*}{ Importação } & \multicolumn{2}{|c|}{ Distribuição } \\
\hline & & Produção & Produção & & Distribuição & Exportação \\
\hline GCN & $\begin{array}{l}\text { São Paulo } \\
\text { Rio de Janeiro } \\
\text { Contagem }\end{array}$ & $\begin{array}{c}\text { Moderada } \\
\text { Fraca } \\
\text { Fraca }\end{array}$ & $\begin{array}{l}\text { Intensa } \\
\text { Moderada } \\
\text { Intensa }\end{array}$ & Predominante & Consumidor & $\begin{array}{l}\text { Forte } \\
\text { Média }\end{array}$ \\
\hline $\mathrm{CN}$ & $\begin{array}{l}\text { Juazeiro } \\
\text { Recife } \\
\text { Goiânia } \\
\text { Curitiba } \\
\text { Campinas } \\
\text { Cariacica } \\
\text { Porto Alegre } \\
\text { Maracanaú } \\
\text { Brasília } \\
\text { Salvador } \\
\end{array}$ & $\begin{array}{c}\text { Intensa } \\
\text { Moderada } \\
\text { Intensa } \\
\text { Intensa } \\
\text { Moderada } \\
\text { Intensa } \\
\text { Moderada } \\
\text { Fraca } \\
\text { Fraca } \\
\text { Fraca } \\
\end{array}$ & $\begin{array}{l}\text { Moderada } \\
\text { Fraca } \\
\text { Moderada } \\
\text { Fraca } \\
\text { Intensa } \\
\text { Fraca } \\
\text { Intensa } \\
\text { Moderada } \\
\text { Moderada } \\
\text { Intensa } \\
\end{array}$ & $\begin{array}{l}\text { Predominante } \\
\text { Predominante }\end{array}$ & $\begin{array}{l}\text { Expedidor } \\
\text { Expedidor } \\
\text { Expedidor } \\
\text { Consumidor } \\
\text { Consumidor } \\
\text { Consumidor }\end{array}$ & $\begin{array}{l}\text { Média } \\
\text { Média }\end{array}$ \\
\hline CR & $\begin{array}{l}\text { Uberlândia } \\
\text { Campo Grande } \\
\text { Caruaru } \\
\text { Maringá } \\
\text { Juiz de Fora }\end{array}$ & $\begin{array}{l}\text { Intensa } \\
\text { Intensa } \\
\text { Fraca } \\
\text { Fraca } \\
\text { Moderada } \\
\end{array}$ & $\begin{array}{l}\text { Moderada } \\
\text { Fraca } \\
\text { Fraca } \\
\text { Fraca } \\
\text { Intensa } \\
\end{array}$ & $\begin{array}{l}\text { Predominante } \\
\text { Predominante }\end{array}$ & $\begin{array}{l}\text { Expedidor } \\
\text { Expedidor } \\
\text { Consumidor }\end{array}$ & \\
\hline ML & $\begin{array}{l}\text { Caxias do Sul } \\
\text { Governador Valadares } \\
\text { Joinville } \\
\text { Caratinga } \\
\text { Cachoeiro de Itapemirim }\end{array}$ & $\begin{array}{c}\text { Intensa } \\
\text { Fraca } \\
\text { Fraca } \\
\text { Intensa } \\
\text { Intensa }\end{array}$ & $\begin{array}{c}\text { Fraca } \\
\text { Moderada } \\
\text { Fraca } \\
\text { Fraca } \\
\text { Fraca }\end{array}$ & $\begin{array}{l}\text { Predominante } \\
\text { Predominante }\end{array}$ & $\begin{array}{l}\text { Consumidor } \\
\text { Consumidor } \\
\text { Consumidor } \\
\text { Expedidor } \\
\text { Consumidor }\end{array}$ & \\
\hline
\end{tabular}

Legenda: GCN - Grande Central Nacional; CN - Central Nacional; CR - Central Regional; ML - Mercado Local.

Quadro 2. Quadro síntese da tipologia funcional de entrepostos atacadistas nacionais.

Cariacica (ES), sendo estas duas últimas também expedidoras para seu entorno. No caso de Porto Alegre e Campinas esta relação com a base produtiva é mais forte no âmbito regional ${ }^{4}$.

Finalmente, São Paulo e Contagem são centrais com funções clássicas de reunião da produção regional, sendo esta mais relevante em São Paulo, inclusive na reunião local. São também Centrais de grande porte de exportação, mas realizada de forma muito mais intensa em São Paulo.

\section{CONCLUSÕES}

O exercício apresentado nesse artigo permitiu observar que o sistema atacadista público de alimentos mudou bastante em relação a sua proposta original desenhada nos anos 70. São poucos os entrepostos que guardam as funções de reunião da produção local

\footnotetext{
${ }^{4}$ Apesar de ser uma central municipal, Campinas tem uma relação mais forte com a base regional do que a local devido ao peso da oferta oriunda de seu principal município fornecedor - Piedade, que também é o principal fornecedor do ETSP da CEAGESP.
}

ou regional permitindo uma maior aproximação entre compradores e vendedores. O conjunto de 23 centrais analisadas apresenta uma enorme heterogeneidade denotando as adaptações e desvios que ocorreram ao longo dos seus 40 anos de existência.

À diferença das décadas anteriores, verifica-se uma elevação do patamar de comercialização de hortigranjeiros nas principais centrais de abastecimento, acompanhada do crescimento real no volume financeiro. $\mathrm{O}$ crescimento do volume financeiro transacionado é dado pelo crescimento da oferta de produtos de maior valor unitário como frutas, nacionais e importadas, influenciadas principalmente no câmbio favorável à importação e no crescimento da renda, indicando que o crescimento da movimentação financeira e quantum no último quinquênio não se baseiam em ganhos de eficiência comercial ou competitiva do segmento atacadista tradicional. Por outro lado, a diminuição ou o crescimento moderado, do volume comercializado dos principais produtos hortigranjeiros confirma que a dinâmica do comércio atacadista destes produtos, com 
poucas exceções, não é mais determinada no âmbito das centrais de abastecimento e sim em outros circuitos comerciais da grande distribuição.

As informações de fornecimento hortigranjeiro dos dez principais municípios fornecedores de 23 entrepostos nacionais, analisadas pelos parâmetros de influência local e regional, permitiram avaliar a funcionalidade sistêmica dos entrepostos nas funções de reunião, importação e distribuição dos produtos hortigranjeiros, de acordo com a escala operacional.

Dois grupos extremos são definidos pelos entrepostos que são puramente importadores, sem relação com a base produtiva local e entrepostos que mantêm a função de reunião local ou regional como função relevante da atividade atacadista, sendo evidenciado o papel da CEAGESP como bub central do sistema, exercendo as funções de reunião local e regional, distribuição e exportação.

Esta tipologia permite estabelecer parâmetros para avaliar o papel exercido pelos entrepostos no sistema nacional, indicando aqueles que mantêm um papel estratégico e relevante na reunião da produção agrícola local e regional e aqueles que se tornaram apenas entrepostos comerciais com pouca ou nenhuma influência sobre a base produtiva local.

\section{REFERÊNCIAS}

[1] Linhares MY, Silva FT. História política do abastecimento (1918-1974). Brasília: Ministério da Agricultura; 1979.

[2] Belik W. Muito além da porteira - mudanças nas formas de coordenação da cadeia alimentar no Brasil. 10 Ed. Campinas: Unicamp; 2001.

[3] Mourão IR. Manual I: Breve história do sistema de CEASAs no Brasil (1960 a 2007). Relatório técnico [acesso em 23 abril 2012]. Disponível em: http://www.ceasa.gov.br/publicaçoes

[4] Cunha ARAA. O sistema atacadista alimentar brasileiro: origens, destinos [tese]. Campinas: Instituto de Economia Unicamp; 2010. $162 \mathrm{p}$.

[5] Chaim NA. Mudanças recentes no comércio varejista de alimentos. Uberlândia: Instituto de Economia, Universidade Federal de Uberlândia; 1999.
[6] Junqueira AH. Centrais de abastecimento: momento decisivo. Revista Agroanalysis. 1999;19(6):14-20.

[7] Carvalho J. Novas estratégias para velhas funções. Revista Hortifruti Brasil. 2006;52:6-26.

[8] Cunha ARAA, Campos JB. Sistema Ceasa: Uma rede complexa e assimétrica de logística. XIII Seminário sobre a economia Mineira. Anais. Diamantina/MG. 2008. 